\title{
IDENTIFYING A FRAMEWORK FOR GRAPHING FORMULAS FROM EXPERT STRATEGIES
}

\author{
Peter Kop $^{1}$, Fred Janssen ${ }^{1}$, Paul Drijvers ${ }^{2}$, Marcel Veenman ${ }^{3}$, Jan van Driel $^{1}$ \\ ${ }^{1}$ Iclon, Leiden University, The Netherlands; ${ }^{2}$ Freudenthal Institute, Utrecht University, \\ The Netherlands; ${ }^{3}$ Institute for Metacognition Research, Hillegom, The Netherlands
}

Graphing formulas with paper and pen helps learners to connect the algebraic and graphical representation of a function, which is important in learning to read algebraic formulas. To be able to graph formulas, a repertoire of functions that can be instantly visualized by a graph (formula-graphics) is necessary, as well as heuristics to tackle more complex functions. Which strategies are essential to graph formulas effectively and efficiently, however, is largely unknown. In this research we identify a framework to describe the variety of strategies for graphing formulas, based on studies of chess expertise. These show that experts use structured knowledge for recognition at different levels, which in turn facilitates the use of search heuristics. Similar interdependence of recognition and heuristic search can be applied to graphing formulas. On this basis a two dimensional framework was formulated, with the dimensions recognition and heuristic search. Five experts and three maths school teachers, who graphed the formula $f(x)=2 x \sqrt{8-x}-2 x$, validated the framework. Participants used different combinations of recognition and heuristic search at different levels. For every participant, the strategy was represented as a path in the framework (see figure). Experts' paths are predominately on the upper and/or left side of the framework; some experts focus on their large repertoire of formula-graphics while others focus on strong heuristics, such as qualitative reasoning about domain, infinity behavior, and symmetry. Both strategies can give efficient results. Not all teachers participating in this study turned out to have sufficient expertise in graphing formulas to complete this task. We conclude that the framework appropriately and discriminatively describes the different observed strategies. The framework can be used to compare teachers' and learners' strategies to those of experts and to design learning trajectories for teachers and learners.

\section{References}

Gobet, F., \& Charness, N. (2006). Chess and games. In K. A. Ericsson, N. Charness, P. Feltovich, \& R. R. Hoffman (Eds.), Cambridge handbook of expertise and expert performance (pp. 523-538). Cambridge, MA: Cambridge University Press.

Romberg, T., Fennema, E., \& Carpenter, T. P. (Eds.). (1993). Integrating research on the graphical representation of functions. Hillsdale, NJ: Lawrence Erlbaum Associates. 